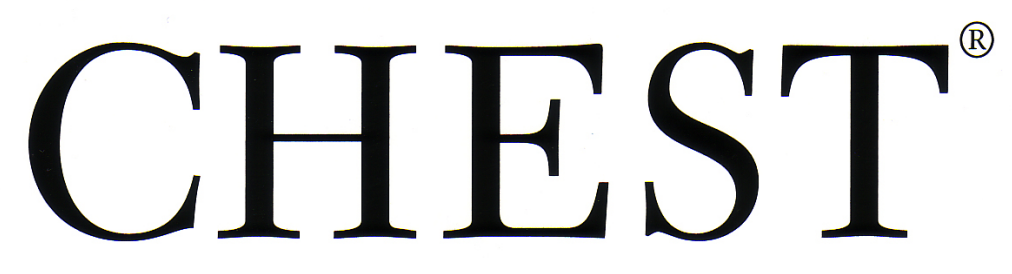

\author{
THE CARDIOPULMONARY \\ AND CRITICAL CARE JOURNAL
}

FOR PULMONOLOGISTS, CARDIOLOGISTS, CARDIOTHORACIC SURGEONS, CRITICAL CARE PHYSICIANS, AND RELATED SPECIALISTS

\author{
Safety, Hemodynamic Profile, and Feasibility of Dobutamine Stress \\ Technetium Myocardial Perfusion Single-Photon Emission CT Imaging for \\ Evaluation of Coronary Artery Disease in the Elderly \\ Abdou Elhendy, Ron T. van Domburg, Jeroen J. Bax, Roelf Valkema, Ambroos E. \\ M. Reijs, Eric P. Krenning and Jos R. T. C. Roelandt \\ Chest 2000;117;649-656 \\ DOI: $10.1378 /$ chest.117.3.649
}

This information is current as of December 4, 2006

The online version of this article, along with updated information and services, is located on the World Wide Web at:

http://www.chestjournal.org/cgi/content/full/117/3/649

CHEST is the official journal of the American College of Chest Physicians. It has been published monthly since 1935 . Copyright 2005 by the American College of Chest Physicians, 3300 Dundee Road, Northbrook IL 60062. All rights reserved. No part of this article or PDF may be reproduced or distributed without the prior written permission of the copyright holder. ISSN: 0012-3692.

A M E R I C A N C O L L E G E O F

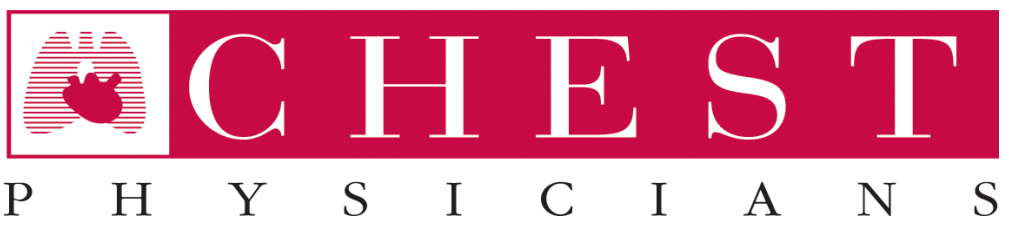




\title{
Safety, Hemodynamic Profile, and Feasibility of Dobutamine Stress Technetium Myocardial Perfusion Single-Photon Emission CT Imaging for Evaluation of Coronary Artery Disease in the Elderly*
}

\author{
Abdou Elhendy, MD, PhD; Ron T. van Domburg, PhD; Jeroen J. Bax, MD, PhD; \\ Roelf Valkema, MD, PhD; Ambroos E. M. Reijs, MSc; \\ Eric P. Krenning, MD, PhD; and Jos R. T. C. Roelandt, MD, PhD
}

\begin{abstract}
Objectives: Cardiovascular disease is the leading cause of morbidity and mortality in the elderly. The evaluation of coronary artery disease by exercise stress testing is frequently limited by the patient's inability to exercise. Although pharmacologic stress testing with dobutamine is an alternative, the safety of dobutamine myocardial perfusion scintigraphy in the elderly has not been previously studied.

Patients and methods: We studied the safety and feasibility of dobutamine (up to $40 \mu \mathrm{g} / \mathrm{kg} / \mathrm{min}$ )atropine (up to $1 \mathrm{mg}$ ) stress myocardial perfusion scintigraphy using technetium single-photon emission CT imaging in 227 patients $\geq 70$ years old (mean \pm SD age, $75 \pm 4$ years). A control group of 227 patients $<70$ years old (mean age, $55 \pm 11$ years; matched for gender, prevalence of previous infarction, $\beta$-blocker therapy, and severity of resting perfusion abnormalities) was studied to assess age-related differences in the safety and the hemodynamic response. A feasible test was defined as the achievement of the target heart rate and/or an ischemic end point (angina, ST-segment depression, or reversible perfusion abnormalities).

Results: No myocardial infarction or death occurred during the test. The target heart rate was achieved more frequently in the elderly patients $(87 \% \mathrm{vs} 79 \%$; $p<0.05)$. The elderly patients had a higher prevalence of supraventricular tachycardia $(7 \%$ vs $1 \% ; p<0.005)$ and premature ventricular contraction $(74 \%$ vs $32 \%$; $p<0.005)$ during the test, as compared to the younger patients. There was a trend to a higher prevalence of ventricular tachycardia (5\% vs $2 \%$ ) and atrial fibrillation $(3 \%$ vs $0.4 \%)$ in the elderly patients. Arrhythmias were terminated spontaneously by termination of dobutamine infusion or by administration of metoprolol. Independent predictors of supraventricular tachyarrhythmias and ventricular tachycardia were older age $\left(\mathrm{p}<0.001 ; \chi^{2}, 9.8\right)$ and myocardial perfusion defect score at rest $\left(\mathrm{p}<0.01 ; \chi^{2}, 6.8\right)$ respectively, by using a multivariate analysis of clinical and stress test variables. Elderly patients had a higher prevalence of systolic BP drop > $20 \mathrm{~mm} \mathrm{Hg}$ during the test $(37 \%$ vs $12 \%$; $<<0.05)$. The test was terminated due to hypotension in $2 \%$ of the elderly patients and in $1 \%$ of the control group. Age was the most powerful predictor of hypotension $\left(\mathrm{p}<0.005 ; \chi^{2}, 10.3\right)$. The test was considered feasible in 216 elderly patients (95\%) and in 209 patients of the control group (92\%).

Conclusion: Dobutamine-atropine stress myocardial perfusion scintigraphy is a highly feasible method for the evaluation of coronary artery disease in the elderly. Elderly patients have a higher risk for developing hypotension and supraventricular tachyarrhythmias during a dobutamine stress test. However, dobutamine-induced hypotension is often asymptomatic and rarely necessitates the termination of the test.

(CHEST 2000; 117:649-656)
\end{abstract}

Key words: arrhythmias; coronary artery disease; dobutamine; elderly; myocardial perfusion; safety

\footnotetext{
${ }^{*}$ From the Thoraxcenter (Drs. Elhendy, van Domburg, Bax, and Roelandt) and the Department of Nuclear Medicine (Drs. Valkema and Krenning and Mr. Reijs), University Hospital Rotterdam-Dijkzigt, Rotterdam, The Netherlands.

This study was supported in part by the Department of Cardiology, Cairo University Hospital, Cairo, Egypt.

Manuscript received March 23, 1999; revision accepted August 13, 1999.

Correspondence to: Abdou Elhendy, MD, PhD, Thoraxcenter, Ba 302, Dr Molewaterplein 40, 3015 GD Rotterdam, The Netherlands
}

Cardiovascular disease is the leading cause of $\checkmark$ morbidity and mortality in the elderly population. ${ }^{1,2}$ Recent advances in revascularization procedures have led to an increase in the number of elderly patients undergoing coronary artery bypass grafting or coronary angioplasty, with a clear benefit on short-term and long-term survival. ${ }^{1,4}$ Therefore, stress testing is justified for the diagnosis and func- 
tional evaluation of coronary artery disease in this population to select patients who are candidates for further interventions. Exercise stress testing is the most widely used noninvasive method for evaluation of coronary artery disease..$^{5}$ However, a larger proportion of the elderly population may be unable to perform exercise stress test due to the higher prevalence of pulmonary airway, degenerative joint, and peripheral vascular diseases, and the reduced physical fitness in the elderly as compared to the younger population. ${ }^{1,6}$ Pharmacologic stress testing in conjunction with myocardial perfusion imaging is an established method for the evaluation of coronary artery disease in patients with limited exercise capacity. ${ }^{7-13}$ Dobutamine perfusion imaging is a feasible method particularly in patients with obstructive airway disease who are not candidates for a vasodilator stress test. ${ }^{9-13}$ Numerous studies have reported the safety of dobutamine stress echocardiography ${ }^{14,15}$ and myocardial perfusion scintigraphy. 9,10 However, the safety of dobutamine perfusion imaging in the elderly has not been reported. Elderly patients are at a higher risk for developing spontaneous and exercise-induced arrhythmias, ${ }^{16,17}$ as well as impairment of compensatory mechanisms for hypotension. Therefore, these patients may be more vulnerable to hypotension and arrhythmias during a dobutamine stress test. The aims of this study are as follows: (1) to assess the safety, feasibility, and hemodynamic profile of dobutamine stress myocardial perfusion scintigraphy in the elderly population with limited exercise capacity who are referred for the diagnosis or functional evaluation of coronary artery disease; and (2) to assess the age-specific differences in the safety and hemodynamic profile by comparing these parameters in the elderly with a control group of younger patients matched for the major clinical characteristics that might influence the safety and feasibility of the test.

\section{Materials AND Methods}

\section{Patient Population}

Study population comprised 227 elderly patients $\geq 70$ years old with limited exercise capacity who were referred for evaluation of myocardial ischemia by dobutamine stress-technetium myocardial perfusion scintigraphy between January 1994 and January 1999 in our imaging laboratory. A group of 227 patients $<70$ years old matched for gender, medication with $\beta$ blockers, previous myocardial infarction, and fixed myocardial perfusion defect score served as control subjects. The test was not performed in patients with severe heart failure, significant valvular heart disease, severe hypertension ( $\mathrm{BP} \geq 180 / 110 \mathrm{~mm} \mathrm{Hg}$ ), hypotension ( $\mathrm{BP}<90 / 60 \mathrm{~mm} \mathrm{Hg}$ ), and unstable chest pain. All patients gave verbal informed consent to undergo the study. The Hospital Ethical Committee approved the use of the dobutamine stress test for evaluation of coronary artery disease.
Clinical Features: The clinical characteristics of patients $\geq 70$ years and $<70$ years old are summarized in Table 1 . There was no significant difference between both groups regarding the prevalence of hypertension, diabetes mellitus, cigarette smoking, previous revascularization, medications at the day of the test, or indications of stress testing. Hypercholesterolemia was more prevalent in the younger group.

\section{Dobutamine Stress Test}

Dobutamine was infused through the antecubital vein starting at a dosage of $5 \mu \mathrm{g} / \mathrm{kg} / \mathrm{min}$ followed by $10 \mu \mathrm{g} / \mathrm{kg} / \mathrm{min}$ (3-min stages), increasing by $10 \mu \mathrm{g} / \mathrm{kg} / \mathrm{min}$ every $3 \mathrm{~min}$ to a maximum of $40 \mu \mathrm{g} / \mathrm{kg} / \mathrm{min}$. Atropine (up to $1 \mathrm{mg}$ ) was given to patients who did not achieve $85 \%$ of maximal heart rate predicted for age and gender (220 - age [in years] beats/min in men and 200 - age beats/min in women) and dobutamine infusion was continued. The ECG was monitored throughout dobutamine infusion and was recorded every minute. Cuff $\mathrm{BP}$ was measured at rest, every 3 min during stress, and at maximal stress. The test was interrupted if severe chest pain, horizontal or downsloping STsegment depression $>2 \mathrm{~mm}$, ventricular or supraventricular tachycardia consisting of $\geq 10$ complexes, hypertension (BP $\geq 240 / 120 \mathrm{~mm} \mathrm{Hg}$ ), systolic BP fall $>40 \mathrm{~mm} \mathrm{Hg}$, or any intolerable side effect regarded as being due to dobutamine occurred during the test. IV metoprolol (from 1 to $5 \mathrm{mg}$ ) was used to reverse the effects of dobutamine if these did not revert quickly.

\section{Single-Photon Emission CT Imaging}

Approximately $1 \mathrm{~min}$ before the termination of the stress test, IV ${ }^{99 m}$ technetium sestamibi, $370 \mathrm{MBq}$, (in 230 patients) or

\begin{tabular}{|c|c|c|c|}
\hline Clinical Features & $\begin{array}{l}\geq 70 \mathrm{yr} \\
(\mathrm{n}=227)\end{array}$ & $\begin{array}{c}<70 \mathrm{yr} \\
(\mathrm{n}=227)\end{array}$ & $\mathrm{p}$ Value \\
\hline Age, yr & $75 \pm 4$ & $55 \pm 11$ & 0.00001 \\
\hline Men $\uparrow$ & $112(49)$ & $112(49)$ & 1 \\
\hline Previous MI $\dagger$ & $81(36)$ & $81(36)$ & 1 \\
\hline Previous CABG & $36(16)$ & $38(17)$ & 0.9 \\
\hline Previous PTCA & $33(15)$ & $36(16)$ & 0.8 \\
\hline History of hypertension & $107(47)$ & $100(44)$ & 0.6 \\
\hline Diabetes mellitus & $34(15)$ & $38(17)$ & 0.7 \\
\hline Cigarette smoking & $44(19)$ & $59(26)$ & 0.1 \\
\hline Hypercholesterolemia & $56(25)$ & $79(35)$ & 0.02 \\
\hline \multicolumn{4}{|l|}{ Medications } \\
\hline$\beta$ blockers $\uparrow$ & $98(43)$ & $98(43)$ & 1 \\
\hline Calcium channel blockers & $106(47)$ & $94(41)$ & 0.3 \\
\hline ACE inhibitors & $67(30)$ & $66(29)$ & 1 \\
\hline \multicolumn{4}{|l|}{ Indications for stress testing } \\
\hline Typical chest pain & $76(33)$ & $70(31)$ & 0.6 \\
\hline Atypical chest pain & $81(36)$ & $69(30)$ & 0.3 \\
\hline Exertional dyspnea or fatigue & $22(10)$ & $25(11)$ & 0.8 \\
\hline $\begin{array}{l}\text { Assessment after } \mathrm{MI} \text { or after } \\
\text { revascularization }\end{array}$ & $48(21)$ & $63(28)$ & 0.1 \\
\hline
\end{tabular}

*Data are presented as mean \pm SD or as No. (\%); MI = myocardial infarction; $\quad \mathrm{CABG}=$ coronary artery bypass graft surgery; PTCA = percutaneous transluminal coronary angioplasty; $\mathrm{ACE}=$ angiotensin-converting enzymes.

$\uparrow$ The two groups were matched for these parameters. 
tetrofosmin (in 224 patients) was administered. The acquisition of stress single-photon emission CT imaging was started $1 \mathrm{~h}$ after the test. Resting studies were performed $24 \mathrm{~h}$ after the stress study and $1 \mathrm{~h}$ after injection of $370 \mathrm{MBq}$ of sestamibi or tetrofosmin. The same isotope administered during stress was used for rest studies. An equal number of patients in each group received the same tracer. Image acquisition and interpretation were performed according to the previously described protocols. ${ }^{10}$ For each study, six oblique (short-axis) slices from the apex to the base and three sagittal (vertical long-axis) slices from the septum to the lateral wall were defined. Each of the six short-axis slices were divided into eight equal segments. The interpretation of the scan was performed using visual analysis assisted by the circumferential profiles analysis. Stress and rest tomographic views were reviewed in side-by-side pairs by an experienced observer who was unaware of the patients' clinical data. A reversible perfusion defect was defined as a perfusion defect on stress images that partially or completely resolved at-rest images in two or more contiguous segments or slices. This was considered diagnostic of ischemia. A fixed perfusion defect was defined as a perfusion defect on stress images in two or more contiguous segments or slices that persisted on rest images. Six major myocardial segments were identified: anterior, inferior, septal anterior, septal posterior, posterolateral, and apical. To assess the severity of perfusion abnormalities, each of the six major left ventricular segments was scored using a 4-grade scoring method $(0=$ normal, $1=$ slightly reduced, $2=$ moderately reduced, and $3=$ severely reduced or absent uptake). The perfusion score was derived using the summation of the scores of the six myocardial segments for rest and stress images. Ischemic score was obtained by subtracting the rest score from the stress score. The rest score (fixed perfusion defect) was considered as the infarction score. ${ }^{10}$ A dobutamine stress test was considered feasible if the patient could achieve $85 \%$ of the maximal heart rate predicted for age and/or when an ischemic end point (angina, ST-segment depression, reversible perfusion abnormalities) was reached.

\section{Statistical Analysis}

Unless specified, data are presented as mean values \pm SD. The $\chi^{2}$ test was used to compare differences between proportions. The Student's $t$ test was used for analysis of continuous data. Stepwise logistic regression models were used to identify inde- pendent predictors of hypotension and arrhythmias. Differences were considered significant if the null hypothesis could be rejected at the 0.05 probability level.

\section{RESULTS}

\section{Hemodynamic Response}

Table 2 summarizes the hemodynamic and dobutamine stress test variables in both groups. Heart rate increased significantly from rest to peak stress in both groups $(\mathrm{p}<0.0001)$. Systolic BP increased significantly in the younger group $(\mathrm{p}<0.0001)$, but not in the elderly group. Diastolic BP dropped more significantly from rest to peak stress in the elderly patients compared to the younger patients $(\mathrm{p}<0.05)$. Elderly patients had a higher baseline systolic BP, a lower peak heart rate, a lower peak rate pressure product, and a higher prevalence of systolic BP drop $>20 \mathrm{~mm} \mathrm{Hg}$. There was no significant difference between both groups regarding the maximal dobutamine dose, frequency of atropine administration, incidence of ST-segment depression, angina, symptomatic hypotension, and minor side effects during the test (Table 3).

The prevalence of various types of arrhythmias during the test is shown in Figure 1. Ventricular and supraventricular tachycardia were terminated in all cases spontaneously by stopping dobutamine infusion or by administration of metoprolol. Ventricular tachycardia consisting of $\geq 10$ beats occurred in two patients (one patient in each group). Elderly patients had a significantly higher prevalence of supraventricular tachycardia and premature ventricular contractions and a trend to a higher prevalence of atrial fibrillation $(\mathrm{p}=0.1)$ and ventricular tachycardia $(\mathrm{p}=0.2)$, compared to the younger patients.

Table 2-Hemodynamic Data of Patients $\geq 70$ and $<70$ Years Old Undergoing Dobutamine-Atropine Stress Myocardial Perfusion Scintigraphy*

\begin{tabular}{|c|c|c|c|}
\hline Hemodynamic and Stress Test Variables & $\begin{array}{c}\geq 70 \mathrm{yr} \\
(\mathrm{n}=227)\end{array}$ & $\begin{array}{c}<70 \mathrm{yr} \\
(\mathrm{n}=227)\end{array}$ & $\mathrm{p}$ Value \\
\hline Heart rate at rest, beats/min & $71 \pm 14$ & $74 \pm 15$ & 0.1 \\
\hline Heart rate at peak stress, beats/min & $126 \pm 15$ & $136 \pm 16$ & 0.0001 \\
\hline Systolic BP at rest, $\mathrm{mm} \mathrm{Hg}$ & $147 \pm 24$ & $137 \pm 23$ & 0.0001 \\
\hline Systolic BP at peak stress, $\mathrm{mm} \mathrm{Hg}$ & $147 \pm 31$ & $147 \pm 29$ & 0.8 \\
\hline Diastolic BP at rest, $\mathrm{mm} \mathrm{Hg}$ & $78 \pm 12$ & $79 \pm 13$ & 0.4 \\
\hline Diastolic BP at peak stress, $\mathrm{mm} \mathrm{Hg}$ & $72 \pm 15$ & $76 \pm 17$ & 0.01 \\
\hline Rate pressure product at rest & $10,522 \pm 2,913$ & $9,521 \pm 2,412$ & 0.2 \\
\hline Rate pressure product at peak stress & $18,510 \pm 4,284$ & $19,953 \pm 4,454$ & 0.0007 \\
\hline Systolic BP drop > $>20 \mathrm{~mm} \mathrm{Hg}$, patients & $48(21)$ & $27(12)$ & 0.01 \\
\hline Systolic BP drop > $40 \mathrm{~mm} \mathrm{Hg}$, patients & $10(4)$ & $5(2)$ & 0.2 \\
\hline Maximal dobutamine dose, $\mu \mathrm{g} / \mathrm{kg} / \mathrm{min}$ & $35.3 \pm 7.6$ & $36.4 \pm 7.2$ & 0.1 \\
\hline Atropine given, patients & $82(36)$ & $94(41)$ & 0.3 \\
\hline Mean atropine, dose, $\mathrm{mg}$ & $0.5 \pm 0.3$ & $0.6 \pm 0.3$ & 0.004 \\
\hline Horizontal or downsloping ST depression, patients & $53(23)$ & $37(16)$ & 0.3 \\
\hline
\end{tabular}

*Data are presented as mean \pm SD or No. (\%). 
Table 3-Symptoms of Patients $\geq 70$ and $<70$ Years Old During Dobutamine-Atropine Stress Myocardial Perfusion Scintigraphy*

\begin{tabular}{lccc}
\hline \hline \multicolumn{1}{c}{ Symptoms } & $\begin{array}{c}\geq 70 \mathrm{yr} \\
(\mathrm{n}=227)\end{array}$ & $\begin{array}{c}<70 \mathrm{yr} \\
(\mathrm{n}=227)\end{array}$ & p Value \\
\hline Nausea & $6(3)$ & $13(6)$ & 0.2 \\
Flushing & $0(0)$ & $1(0.4)$ & 0.1 \\
Dizziness & $10(4)$ & $5(2)$ & 0.3 \\
Anxiety & $4(2)$ & $6(3)$ & 0.7 \\
Chills & $17(7)$ & $13(6)$ & 0.6 \\
Headache & $15(7)$ & $11(5)$ & 0.5 \\
Symptomatic hypotension & $4(2)$ & $2(1)$ & 0.7 \\
Typical angina & $68(30)$ & $52(23)$ & 0.1 \\
\hline
\end{tabular}

*Data are presented as No. $(\%)$.

\section{Test End Points}

The reasons for termination of the test in both groups are listed in Table 4 . The test was terminated because of reaching the target heart rate more frequently in the elderly group. The test was terminated due to angina, ST-segment changes, arrhythmias, hypotension, hypertension, and other minor side effects in a similar proportion of both groups, whereas the younger patients had a higher rate of failure to reach the target heart rate, despite the maximal dose of dobutamine and atropine. Nineteen elderly patients and 34 of the younger patients could not achieve the target heart rate and had no angina or ST-segment depression. Reversible perfusion defects were detected in 8 and 16 of these patients, respectively, resulting in a feasible test (achievement of the target heart rate or an ischemic end point) in 216 elderly patients (95\%) and in 209 of the younger patients $(92 \%)$.

\section{Myocardial Perfusion Scintigraphy}

The prevalence of different perfusion scintigraphic patterns in both groups is shown in Figure 2. There was no significant difference between both groups regarding the prevalence of reversible or fixed perfusion defects.

\section{Gender Differences}

Women had a higher prevalence of normal myocardial perfusion ( $56 \%$ vs $23 \%$; $\mathrm{p}<0.001$ ), a lower infarction score $(1.1 \pm 2.2$ vs $3 \pm 3 ; \mathrm{p}<0.0001)$, and a lower ischemic score $(0.8 \pm 1.7$ vs $1.6 \pm 2.4$; $\mathrm{p}<0.0001)$ compared to men, respectively. There was no significant difference regarding the stress rate pressure product between men and women in the elderly group $(18,707 \pm 4,508$ vs $18,304 \pm 4,027)$ or in the younger group $(19,967 \pm 4,223$ vs $19,940 \pm$ $4,810)$, respectively.

\section{Sestamibi vs Tetrofosmin Studies}

Patients who underwent sestamibi imaging had a higher ischemic score than patients who underwent tetrofosmin imaging $(1.4 \pm 2.1$ vs $0.8 \pm 1.5$; $\mathrm{p}<0.005)$. The infarction score was not significantly different between both groups $(2.1 \pm 2.7$ vs $1.9 \pm 2.8$, respectively; $\mathrm{p}=0.4$ )

\section{Predictors of Hypotension and Arrhythmias}

Clinical and stress test variables included in the multivariate analysis model were as follows: age, gender, history of angina, previous myocardial infarction, hypertension, baseline systolic BP, medications, maximal dobutamine dose, peak heart rate, abnormal perfusion, fixed and ischemic perfusion defect scores, and angina during the test. Independent predictors of systolic BP drop $>20 \mathrm{~mm} \mathrm{Hg}$ during stress were older age $\left(p<0.005 ; \chi^{2}, 10.3\right)$, a higher stress heart rate $\left(\mathrm{p}<0.01 ; \chi^{2}, 7.7\right)$, a higher baseline systolic BP $\left(\mathrm{p}<0.05 ; \chi^{2}, 5.1\right)$, medication with calcium antagonists $\left(\mathrm{p}<0.05 ; \chi^{2}, 4.1\right)$, and a higher dobutamine dose $\left(\mathrm{p}<0.05 ; \chi^{2}, 4.7\right)$. The only independent predictor of supraventricular tachyarrhythmias (supraventricular tachycardia and atrial fibrillation) was older age $\left(p<0.001 ; \chi^{2}, 9.8\right)$. The infarction (rest perfusion defect) score was the only independent predictor of ventricular tachycardia $\left(\mathrm{p}<0.01 ; \chi^{2}, 6.8\right)$.

\section{Discussion}

As far as we are concerned, this is the first study that evaluates the safety and feasibility of dobutamine stress myocardial perfusion scintigraphy in the elderly. The mean age of the elderly patients in our study was 75 years. These patients represented the usual candidates for pharmacologic stress testing at this age group who are unable to perform an exercise stress test. Referring patients at this age for the noninvasive evaluation of coronary artery disease reflects the confidence of physicians regarding the beneficial effects of guided therapeutic interventions in the elderly. A group of younger patients was used as a control group in this study. The patients were matched for the major clinical features that may have an influence on the hemodynamic profile and the safety of the test. The patients were matched for gender because previous studies have shown genderrelated difference in the chronotropic response and safety. ${ }^{18,19}$ The severity of resting perfusion abnormalities (and presumably left ventricular dysfunction) was also selected among matching parameters because the extent of myocardial perfusion abnormalities was reported to predict complications dur- 


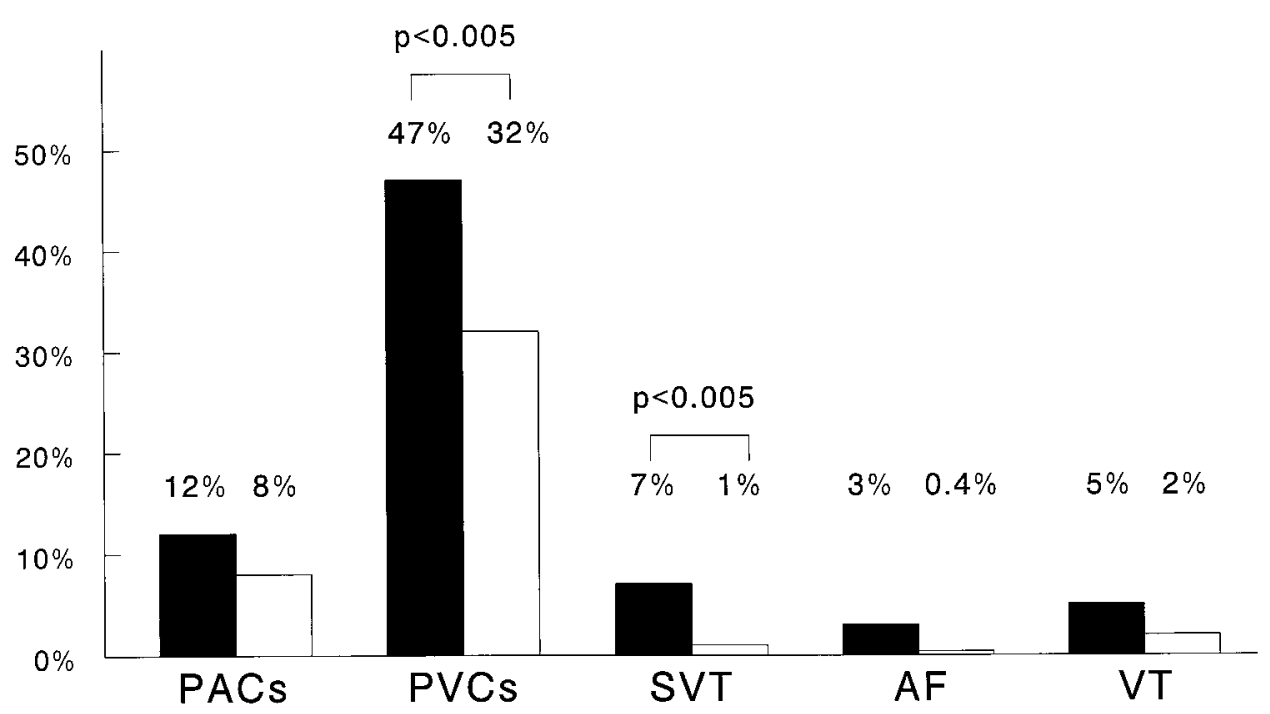

FIGURE 1. The prevalence of various types of arrhythmias during dobutamine stress test in patients $\geq 70$ years old and $<70$ years old. $y=$ years old; PACs $=$ premature atrial contractions; $\mathrm{PVCs}=$ premature ventricular contractions; SVT = supraventricular tachycardia; $\mathrm{AF}=$ atrial fibrillation; $\mathrm{VT}=$ ventricular tachycardia.

ing the test. ${ }^{10}$ Finally, the patients were matched for the treatment with $\beta$ blockers because these agents interfere with the chronotropic response to dobutamine and therefore may reduce the feasibility of the test, increase the need for atropine administration, or reduce the prevalence and severity of inducible ischemia. ${ }^{20}$ On the other hand, the intake of $\beta$ blockers may be associated with more complications, presumably because these medications are prescribed to patients with a higher risk profile, as are patients with previous myocardial infarction, typical angina, and hypertension. ${ }^{19}$ Therefore, matching the two groups allowed an independent detection of any possible age-specific difference in the hemodynamic and safety profile of the dobutamine stress test. This matching explains the nearly similar clinical features

Table 4-Reasons for Termination of Dobutamine Stress Testing in Patients $\geq 70$ and $<70$ Years Old $*$

\begin{tabular}{lccc}
\hline \hline \multicolumn{1}{c}{ Reasons for Test Termination } & $\begin{array}{c}\geq 70 \mathrm{yr} \\
(\mathrm{n}=227)\end{array}$ & $\begin{array}{c}<70 \mathrm{yr} \\
(\mathrm{n}=227)\end{array}$ & $\mathrm{p}$ Value \\
\hline 85\% of maximal heart rate & $197(87)$ & $180(79)$ & 0.045 \\
Maximal dose & $8(4)$ & $29(13)$ & 0.001 \\
Angina & $7(3)$ & $9(4)$ & 0.8 \\
ST changes & $4(2)$ & $4(2)$ & 1 \\
Arrhythmias & $3(1.3)$ & $1(0.4)$ & 0.6 \\
Hypertension & $2(0.9)$ & $1(0.4)$ & 0.7 \\
Hypotension & $5(2)$ & $2(1)$ & 0.3 \\
Chills, flushing, anxiety, dizziness & $1(0.4)$ & $1(0.4)$ & 1 \\
\hline
\end{tabular}

*Data are presented as No. (\%). of the two groups of patients, as shown in Table 1. Our study demonstrated that dobutamine myocardial perfusion scintigraphy is a highly feasible method for the noninvasive evaluation of coronary artery disease in the elderly. Ninety-five percent of these patients could achieve the end point of target heart rate and/or an ischemic end point.

Heart Rate Response: A higher proportion of the elderly patients could achieve the target heart rate. This may be related to a higher dose-related response due to age-related changes in the pharmacokinetics of the drugs. Another explanation is the lower calculated target heart rate in the elderly that renders the achievement of the target heart rate easier in older patients. ${ }^{5}$ This can also explain the lower peak heart rate in the elderly. Despite the fact that previous studies have demonstrated that elderly subjects have a reduced sensitivity to sympathetic stimulation, ${ }^{21}$ it has been recently shown that the cardiac chronotropic response to $\beta$-receptor adrenergic stimulation is not reduced in the elderly. ${ }^{22}$

BP Response: Systolic BP increased significantly from rest to peak stress in the younger patients but not in the elderly patients. Diastolic BP dropped more significantly from rest to peak stress in the elderly patients compared to the younger patients. Additionally, the prevalence of hypotension during the test was significantly higher in the elderly pa- 


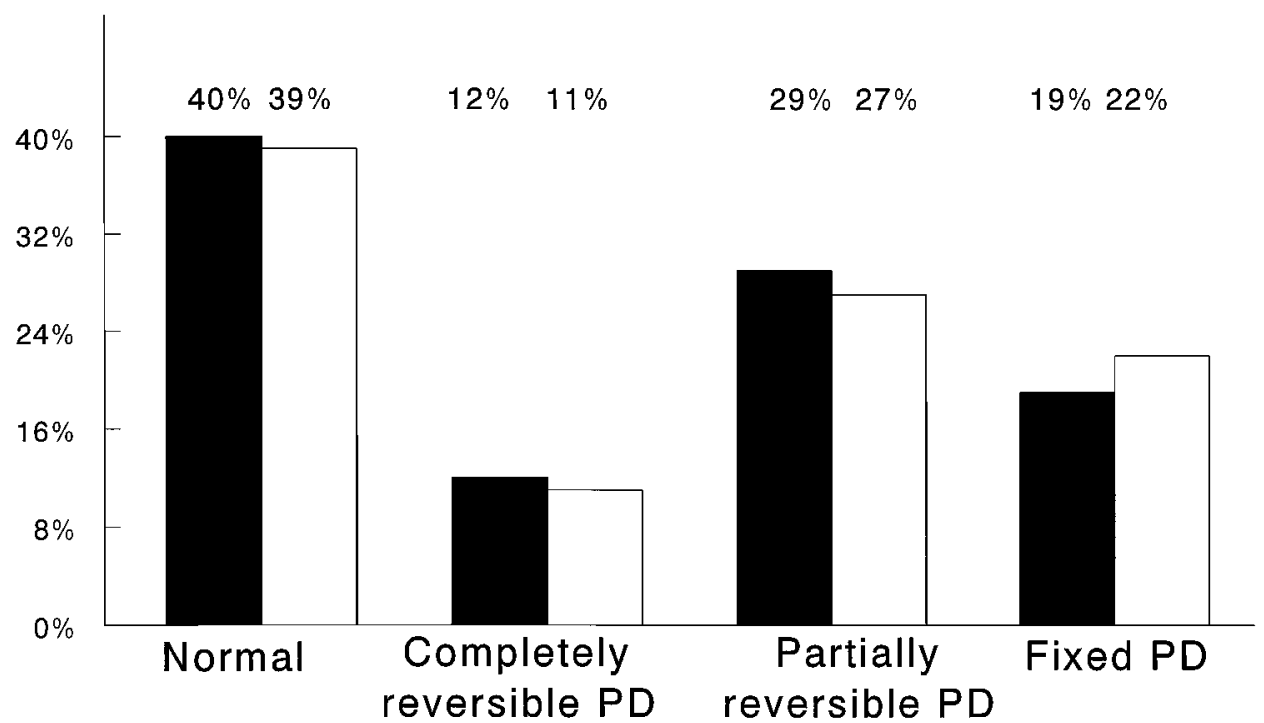

FIGURE 2. The prevalence of myocardial perfusion abnormalities in patients $\geq 70$ years old and $<70$ years old undergoing dobutamine stress test. PD = perfusion defect; see Figure 1 for abbreviation.

tients. However, most of the episodes of hypotension were asymptomatic, and the test was terminated because of hypotension only in five patients $(2 \%)$. The test was terminated because of marked systolic $\mathrm{BP}$ increase in two elderly patients and in one younger patient. The impairment of systolic BP response to dobutamine in the elderly patients may be explained by different mechanisms. These include the impairment of compensatory mechanism for hypotension with aging, ${ }^{23}$ rendering the patients susceptible to hypotension induced by the action of dobutamine on $\beta_{2}$ receptors with subsequent peripheral vasodilation. It has also been demonstrated that elderly subjects maintain cardiac output during exercise by an increase in the end-diastolic dimension. ${ }^{24}$ Since dobutamine infusion causes a significant reduction of the end-diastolic dimension, ${ }^{25,26}$ this may deprive the subject from this compensatory mechanism. Peripheral vasodilatation induced by dobutamine may further compromise diastolic filling of the left ventricle. This contention is supported by our finding that dobutamine dose and medication with calcium channel blockers were independent predictors of hypotension during the test. Finally, the elderly had higher baseline systolic BP compared to the younger patients. A higher baseline systolic BP was reported to predict hypotension during dobutamine stress test. ${ }^{14,19}$ In this study, both the age and the baseline systolic BP were independently associated with dobutamine-induced hypotension, which demonstrates that the higher baseline systolic BP in the elderly was contributing (but was not the sole underlying mechanism) to dobutamine-induced hypotension in the elderly.

Arrhythmias: Elderly patients had a higher prevalence of supraventricular tachycardia ( $7 \%$ vs $1 \%$ ), atrial fibrillation ( $3 \%$ vs $0.4 \%$ ), and premature ventricular contraction ( $74 \%$ vs $32 \%$ ) during the test compared to the younger patients. There was also a trend to a higher prevalence of ventricular tachycardia in the elderly ( $5 \%$ vs $2 \%$ ). However, the tachycardia was terminated spontaneously by termination of dobutamine infusion or by administration of metoprolol. No myocardial infarction or death occurred in any patient. The test was terminated because of arrhythmias in four patients (three in the elderly and one in the younger patients). Age was an independent predictor of supraventricular tachyarrhythmias. Previous studies have demonstrated an increased prevalence of spontaneous and exercise-induced arrhythmias with aging, ${ }^{16,17}$ which might explain the higher prevalence of tachyarrhythmias (particularly supraventricular tachycardia and premature ventricular contractions) in the elderly patients in this study. A trend was found to a higher prevalence of ventricular tachycardia in the elderly. However, the severity of resting perfusion abnormalities (and, presumably, resting left ventricular dysfunction) was the only independent predictor of the occurrence of ventricular tachycardia. This may be explained by the higher probability of the presence of substrate for 
arrhythmias in patients with more severe left ventricular dysfunction. ${ }^{10}$

\section{Studies of Dobutamine Stress Echocardiography} in the Elderly: Few reports are available regarding the safety of dobutamine stress echocardiography in the elderly. These studies included smaller numbers of patients compared to our study and did not compare the results with a control group, ${ }^{27-29}$ or compared the elderly with a younger population unmatched for clinical variables that may influence the safety and feasibility of the dobutamine stress test. ${ }^{19}$ Poldermans et al $^{27}$ studied 179 patients $\geq 70$ years old by dobutamine-atropine stress echocardiography. Arrhythmias induced during the test were atrial fibrillation in $2 \%$, nonsustained ventricular tachycardia in $2 \%$, and premature ventricular contractions in $21 \%$. Hypotension occurred in $4 \%$. No control group was studied. Baudhuin et al $^{28}$ studied 63 patients $\geq 60$ years old compared to 63 patients $<60$ years old by dobutamine stress echocardiography. Sensitivity and specificity of dobutamine echocardiography for the diagnosis of coronary artery disease were $80 \%$ and $75 \%$ in the older patients and $79 \%$ and $88 \%$ in the younger patients, respectively. The prevalence of minor side effects was similar in both groups. Hiro et al ${ }^{19}$ studied 106 patients $\geq 75$ years old by dobutamine stress echocardiography. Elderly patients had a higher prevalence of symptomatic hypotension and ventricular arrhythmias and a similar prevalence of supraventricular arrhythmias as compared to the younger patients. In their study, age was an independent predictor of hypotension but not of arrhythmias. However, the prevalence of different types of supraventricular or ventricular arrhythmias was not reported. Anthopoulos et al ${ }^{29}$ studied 120 elderly patients who underwent coronary angiography by dobutamine echocardiography. Sensitivity, specificity, and accuracy of dobutamine echocardiography for the diagnosis of coronary artery disease were $86.5 \%, 84 \%$, and $86 \%$, respectively. Although the use of echocardiographic imaging during dobutamine infusion was shown in previous studies to have a reasonable accuracy for the detection of coronary artery disease in the elderly, this study shows that myocardial perfusion imaging is a feasible alternative and should be considered, particularly in centers without adequate experience in stress echocardiographic imaging.

\section{Clinical Implications and Conclusion: Dobut-} amine-atropine stress myocardial perfusion scintigraphy is a highly feasible method for the evaluation of coronary artery disease in the elderly. The target heart rate is achieved more frequently during the test in elderly patients than in younger patients.
Elderly patients are at increased risk for developing supraventricular tachyarrhythmias during a dobutamine stress test. Although dobutamine-induced hypotension is more frequent in elderly patients, it is often asymptomatic and rarely necessitates termination of the test.

\section{REFERENCES}

1 Schulman SP, Fleg JL. Stress testing for coronary artery disease in the elderly. Clin Geriatr Med 1996; 12:101-191

2 Coodley EL. Clinical spectrum and diagnostic techniques of coronary heart disease in the elderly. J Am Geriatr Soc 1988; 36:447-456

3 Gersh BJ, Kronmal RA, Schaff HV, et al. Comparison of coronary artery bypass surgery and medical therapy in patients 65 years of age or older. N Engl J Med 1987; 313:217-224

4 Peterson ED, Jollis JB, Bebchuk JD, et al. Changes in mortality after myocardial revascularization in the elderly: the national Medicare experience. Ann Intern Med 1994; 121 : 919-927

5 Sheffield LT. Exercise stress test. In: Braunwald E, ed. Heart disease: a textbook of cardiovascular medicine. 4th ed. Philadelphia, PA: WB Saunders, 1988; 223-241

6 Riley CP, Oberman A, Lampton TD, et al. Submaximal exercise testing in a random sample of elderly population. Circulation 1970; 62:43-52

7 Lette J, Tatum JL, Fraser S, et al. Safety of dipyridamole testing in 73,806 patients: the multicenter dipyridamole safety study. J Nucl Cardiol 1995; 2:3-17

8 Cerqueria MD, Verani MS, Schwaiger M, et al. Investigations of the Multicenter Adenoscan Trials: safety profile of adenosine stress perfusion imaging; results from the adenoscan multicenter trial registry. J Am Coll Cardiol 1994; 23:384-389

9 Dakik HB, Vempathy H, Verani MS. Tolerance, hemodynamic changes and safety of dobutamine stress perfusion imaging. J Nucl Cardiol 1996; 3:410-414

10 Elhendy A, Valkema R, van Domburg RT, et al. Safety of dobutamine-atropine stress myocardial perfusion scintigraphy. J Nucl Med 1998; 39:1662-1666

11 Pennell DJ, Underwood SR, Swanton RH, et al. Dobutamine thallium myocardial perfusion tomography. J Am Coll Cardiol 1991; 18:1471-1479

12 Hays JT, Mahmarian JJ, Cochran AJ, et al. Dobutamine thallium-201 tomography for evaluating patients with suspected coronary artery disease unable to undergo exercise or vasodilator pharmacologic stress testing. J Am Coll Cardiol 1993; 21:1583-1590

13 Geleijnse ML, Elhendy A, van Domburg RT, et al. Prognostic value of dobutamine-atropine stress technetium-99m sestamibi perfusion scintigraphy for evaluation of ischemic heart disease. J Am Coll Cardiol 1996; 28:447-454

14 Elhendy A, van Domburg RT, Roelandt JRTC, et al. Safety and feasibility of dobutamine-atropine stress testing in hypertensive patients. Hypertension 1997; 29:1232-1239

15 Geleijnse ML, Fioretti PM, Roelandt JRTC. Methodology, feasibility safety and diagnostic accuracy of dobutamine stress echocardiography. J Am Coll Cardiol 1997; 30:595-606

16 Maurer MS, Shafrin EA, Fleg JL. Prevalence and prognostic significance of exercise-induced supraventricular tachycardia in apparently healthy volunteers. Am J Cardiol 1995; 75:788792

17 Mayuga R, Arrington CT, O'Connor FC, et al. Why do exercise-induced ventricular arrhythmias increase with age? 
Role of M-mode echocardiographic aging changes. J Gerontol A Biol Sci Med Sci 1996; 51:M23-M28

18 Marcovitz PA, Bach DS, Mathias W, et al. Paradoxic hypotension during dobutamine stress echocardiography: clinical and diagnostic implications. J Am Coll Cardiol 1993; 21 : $1080-1086$

19 Hiro J, Hiro T, Reid CL, et al. Safety and results of dobutamine stress echocardiography in women versus men and in patients older and younger than 75 years of age. Am J Cardiol 1997; 80:1014-1020

20 Fioretti PM, Poldermans D, Salustri A, et al. Atropine increases the accuracy of dobutamine stress echocardiography in patients taking beta-blockers. Eur Heart J 1994; 15:355-360

21 Kendall MJ, Woods KL, Wilkins MR, et al. Responsiveness to beta-adrenergic receptor stimulation: the effects of age are cardioselective. Br J Clin Pharmacol 1982; 14:821-826

22 Poldermans D, Boersma E, Fioretti PM, et al. Cardiac chronotropic responsiveness to beta-adrenoceptor stimulation is not impaired in the elderly. J Am Coll Cardiol 1995; 25:995-999

23 Lipsitz LA. Abnormalities in blood pressure homeostasis that contribute to falls in the elderly. Clin Geriatr Med 1985; 3:637-648
24 Rodeheffer RJ, Gerstenblith G, Becker LC, et al. Exercise cardiac output is maintained with advancing age in healthy human subjects: cardiac dilatation and increased stroke volume compensate for a diminished heart rate. Circulation 1984; 69:203-213

25 Tanimoto M, Pai RG, Jintapakorn W, et al. Mechanism of hypotension during dobutamine stress echocardiography in patients with coronary artery disease. Am J Cardiol 1995; 76:26-30

26 Ruffolo RR. The pharmacology of dobutamine. Am J Med Sci 1987; 294:244-248

27 Poldermans D, Fioretti P, Boersma E, et al. Dobutamineatropine stress echocardiography in elderly patients unable to perform an exercise test. Arch Intern Med 1994; 154:26812686

28 Baudhuin T, Marwick T, Melin J, et al. Diagnosis of coronary artery disease in elderly patients: safety and efficacy of dobutamine echocardiography. Eur Heart J 1993; 6:799-803

29 Anthopoulos LP, Bonou MS, Kardaras FG, et al. Stress echocardiography in elderly patients with coronary artery disease: applicability, safety and prognostic value of dobutamine and adenosine echocardiography in elderly patients. J Am Coll Cardiol 1996; 28:52-59 
Safety, Hemodynamic Profile, and Feasibility of Dobutamine Stress

Technetium Myocardial Perfusion Single-Photon Emission CT Imaging for

Evaluation of Coronary Artery Disease in the Elderly

Abdou Elhendy, Ron T. van Domburg, Jeroen J. Bax, Roelf Valkema, Ambroos E.

M. Reijs, Eric P. Krenning and Jos R. T. C. Roelandt

Chest 2000;117;649-656

DOI: $10.1378 /$ chest.117.3.649

This information is current as of December 4, 2006

Updated Information

\& Services

References

Citations

Permissions \& Licensing

Reprints

Email alerting service

Images in PowerPoint format
Updated information and services, including high-resolution figures, can be found at:

http://www.chestjournal.org/cgi/content/full/117/3/649

This article cites 28 articles, 14 of which you can access for free at:

http://www.chestjournal.org/cgi/content/full/117/3/649\#BIBL

This article has been cited by 4 HighWire-hosted articles: http://www.chestjournal.org/cgi/content/full/117/3/649\#othera rticles

Information about reproducing this article in parts (figures, tables) or in its entirety can be found online at:

http://www.chestjournal.org/misc/reprints.shtml

Information about ordering reprints can be found online: http://www.chestjournal.org/misc/reprints.shtml

Receive free email alerts when new articles cite this article sign up in the box at the top right corner of the online article.

Figures that appear in CHEST articles can be downloaded for teaching purposes in PowerPoint slide format. See any online article figure for directions.

$\begin{array}{llllllllll}\mathrm{P} & \mathrm{H} & \mathrm{Y} & \mathrm{S} & \mathrm{I} & \mathrm{C} & \mathrm{I} & \mathrm{A} & \mathrm{N} & \mathrm{S}\end{array}$

